\title{
Deep Vein Thrombosis and Pulmonary Embolism in a Woman with Uterine Myoma
}

\author{
R. NAWAZ, S. HAQUE, K. SHAHA
}

\begin{abstract}
:
Background: Deep vein thrombosis and pulmonary embolism are rare complications of uterine myoma. There have been few reports on these associations.

Case: A 41 year old para 1+0 presented with 20 weeks size fibroid uterus, which had compressed the pelvic veins and caused unilateral deep vein thrombosis of right leg with subsequent pulmonary embolism. After anticoagulation therapy, a total abdominal hysterectomy was performed, with an uneventful recovery.

Conclusion: Although deep vein thrombosis and pulmonary embolism associated with uterine myoma is a rare event, it can be managed successfully with anticoagulants and hysterectomy. A uterine myoma with deep vein thrombosis and pulmonary embolism is an indication for hysterectomy.
\end{abstract}

\section{Introduction:}

The association between uterine leiomyoma (fibroids) and venous thromboembolism is infrequently reported in the medical literature,eight such cases in English literature ${ }^{(1-8)}$ and three in other language ${ }^{(9-12)}$. The majority of these cases assumed to be secondary to the direct compressive effect of massive fibroid on the blood vessel wall. ${ }^{(13,14)}$. We encountered such a case of uterine myoma complicated preoperatively by formation of deep vein thrombosis and pulmonary thromboembolism. There was no other risk factor for venous thromboembolic disease in this case. Here we present the clinical course and treatment of the case and discuss some problems in managing such patient.

\section{Case:}

A 41 years old, para 1+0, Bangladeshi woman presented in the MHC (master health check up) clinic of Apollo Hospital Dhaka with the complains of moderate dysmenorrhoea and menorrhagia for last 6 months. All the clinical findings and investigation reports were unremarkable, except a clinical and ultra sonogram confirmed evidence of fibroid uterus which was more than 20 weeks pregnancy size. She had an uncomplicated normal vaginal delivery 21 years back and was not taking any contraception as she was single. Her BMI was 25 . On view of her increasing dysmenorrhea with a huge fibroid she was counselled for total abdominal hysterectomy/myomectomy. She refused any operative treatment and opted for medical management to relief her symptoms. We prescribed her mefenamic acid and tranexamic acid for symptomatic relief.

Six months later she presented in gynaecological out patient department with the complain of palmer swelling with difficulty in stepping of her right lower limb. Deep vein thrombosis of right leg was suspected and confirmed by Colour Doppler blood flow studies, which revealed multiple deep vein thrombosis (near complete) of (1) right proximal superficial femoral, (2) right popliteal, (3) right posterior and anterior tibial vein and (4) thrombosis of right lesser saphanous vein. She was immediately admitted in the cardiology department of Apollo Hospital Dhaka and treated with $60 \mathrm{mg}$ subcutaneous heparin twice daily. Three units of packed cells were transfused because her haemoglobin was dropped to $5.8 \mathrm{~g} / \mathrm{dl}$ due to increasing menorrhagia. Enoxaparin (LMWH) was replaced by warfarin on the $5^{\text {th }}$ day of hospitalization when her pain and swelling of right leg subsided. She was subsequently managed as an out patient, with regular monitoring of international normalised ratio (INR) for adjustment of doses of warfarin. 


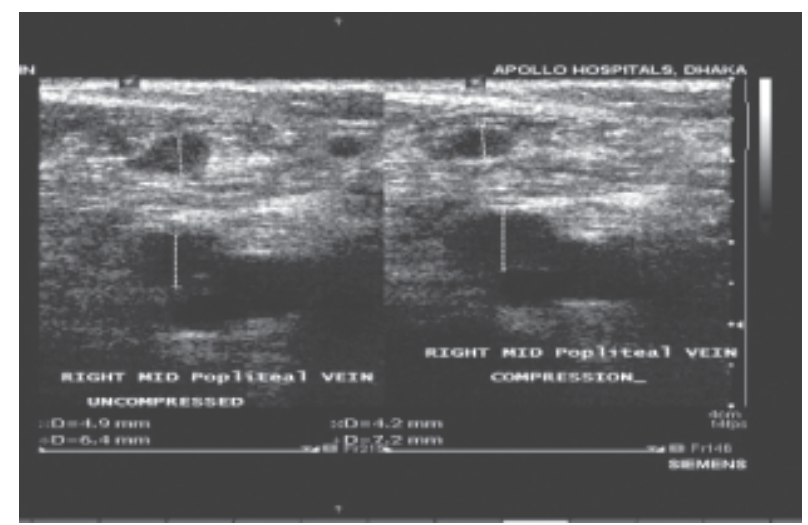

Doppler blood flow study showing echogenic materials consistent with thrombus occluding the lumen of the right mid popliteal vein. No change of luminal size on compression.

One and half months later she again presented in the out patient department of cardiology with feeling of coldness of both upper limbs, when spiral CT Scan chest (contrast) demonstrated a non enhancing thrombus in distal right main pulmonary artery extending to right lower lobar branch with moderate to severe luminal narrowing. There was also appearance of thrombus into the left femoral vein as revealed by repeat Doppler blood studies. She was readmitted for intensive monitoring when subcutaneous LMWH was reinstituted. Her deep vein thrombosis and pulmonary embolism was gradually improved in several weeks time with intensive monitoring and treatment by parenteral heparin therapy but her menorrhagia and dysmenorrhea were getting worse. So total abdominal hysterectomy was planned. Before the operative treatment $\mathrm{CT}$ angiogram was repeated which confirmed recanalization of the thrombi in the pulmonary artery and both the leg veins.

Total abdominal hysterectomy was performed under prophylactic LMWH, just one year after her first visit in Apollo hospital. A large myomatous uterus was removed weighing $2.8 \mathrm{~kg}$. Her postoperative course was uneventful. On third postoperative day heparin therapy was discontinued and warfarin reinstituted. The histopathological diagnosis confirmed a benign tumour of the myometrium. CT Doppler studies performed three months later while the patient was still receiving warfarin sodium. The study demonstrated patent leg veins.

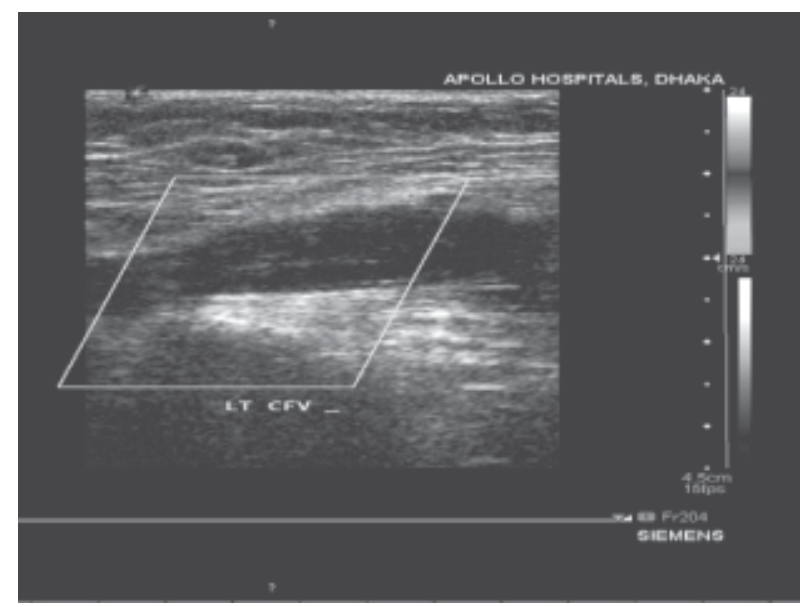

Evidence of deep vein thrombosis in left common iliac vein.

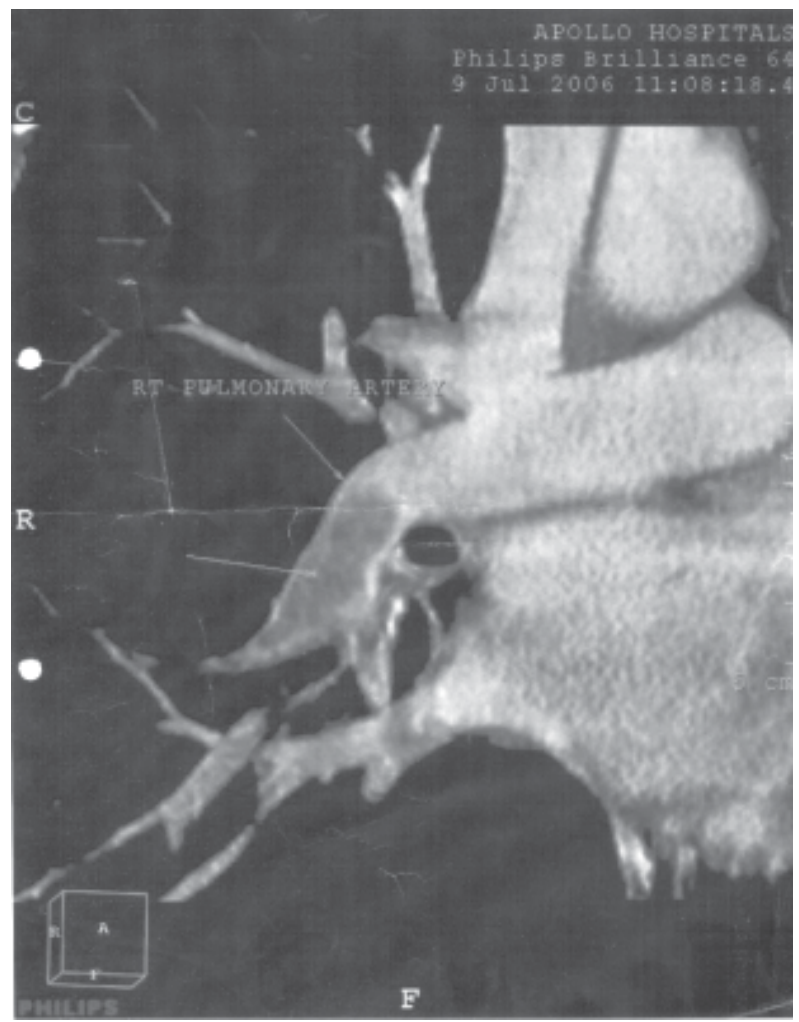

Pulmonary angiogram showing non-enhancing thrombus in the distal right main pulmonary artery and extending to right lower lobar branch with moderate to severe luminal narrowing.

\section{Discussion:}

The main predisposing factor leading to DVT followed by pulmonary embolism was the huge uterine fibroid, perhaps resulting in chronic venous stasis in the lower limbs ${ }^{12}$. The Colour Doppler blood flow studies with CT scan and pulmonary angiogram were important 
diagnostic tools of marked deep vein thrombosis and pulmonary embolism. Our patient had no other risk factors including immobilization, cancer, surgery, fracture, paralysis and use of oral contraceptive ${ }^{(15,}$ 16). Her BMI was 25 , although obesity is not a clear risk factor ${ }^{13}$. The patient was a non smoker and clinical examination ruled out any other possible prothrombotic conditions. We did not prescribe her norethisterone for medical management of menorrhagia although norethisterone has not been associated with vascular thrombotic events, but high doses have been reported to cause a transient hypercoagulable state in Asian women ${ }^{17}$. Rosendaal ${ }^{18}$ stated that the incidence of thrombosis increases sharply with age from 1 per 100,000 people per year in childhood to merely $1 \%$ per year in old age. Age seem to increase the thrombus potential probably as a result of wear and tear on the vessels and their valves, or factors such as decreased mobility. There had been about 21 years gap between the patient's normal vaginal delivery and the onset of DVT. Based on Rosendaal theory, the risk of DVT when her huge uterine fibroid was diagnosed was greater, than the risk of DVT during the pregnancy and peurperium.

Although the patient initially had progressive deep vein thrombosis and pulmonary embolism in spite of heparin followed by warfarin treatment, she subsequently improved. It was reported that most venous thrombi are clinically silent without typical symptom. It is important not to overlook DVT of the leg or pelvic vein on preoperative image evaluation of large uterine myoma using USG, CT and MRI. Because of the presence of two predominating conditions, thrombotic disease and myomatous uterus, we decided on a combined approach; first medical treatment with anticoagulants to improve deep vein thrombosis and pulmonary embolism, followed by surgical treatment (hysterectomy) for the underlying disease. There was no operative difficulty, and no complication was noted postoperatively.

Insertion of umbrella device into the inferior venacava preoperatively to prevent extension of thrombus as suggested in other articles was not undertaken in this case since CT angiogram performed preoperatively during the course of anticoagulant therapy revealed satisfactory recanalization of multiple thrombi.

\section{References:}

1. Hawes J, Lohr J, Blum B, Bhati A, Bhaskaram $J$, Engel $A$. Large uterine fibroid causing mechanical obstruction of the inferior venacava and subsequent thrombosis : a case report. Vasc Endovascular Surg 2006 Oct-Nov; 40(5):425-7.

2. Falcome M, Serra P. Massive pulmonary embolism in a woman with leiomyomatous uterus causing pelvic deep venous thrombosis. Ann Ital Med Int 2005 Apr-Jun; 20(2):104-7.

3. Tanaka H, Umekawa T, Kikukawa T, Nakamura $\mathrm{M}$, Toyoda N. Venous thromboembolic disease associated with uterine myomas diagnosed before hysterectomy : a report of two cases. J Obstet Gynaecol Res 2002 Dec; 28(6):300-3.

4. Phupong V. Tresukosol D, Taneepanichskul S, Boonkasemsanti W. Unilateral deep vein thrombosis associated with a large myoma uteri : a case report. J Reprod Med 2001 Jun; 46(6):618-20.

5. Stanko CM, Severson MA $2^{\text {nd }}$, Molpus KL. Deep venous thrombosis associated with large leiomyomata uteri. A case report. J Reprod Med 2001 Apr; 46(4):104-7.

6. Mishikawa $\mathrm{H}$, Ideishi M, Nishimra J, Kawa mura A, Kanochi H, Tahara H, Tsuchiya Y, Shirai K, Okabe M, Arakawa K. Deep venous thrombosis associated with large uterine myoma - a case report. Angiology 2000 Feb; 51(2):161-6.

7. Dekel A, Rabinerson D, Dicker D, Ben-Rafael Z. Thrombosis of the pelvis veins associated with a large myomatous uterus. Obstet Gynaecol 1998 Oct; 92(4 Pt 2):646-7.

8. Chong YS, Fong YF, Chyne NgS. Deep vein thrombosis in patient with large uterine myomata. Obstet Gynaecol 1998; 92:-707.

9. Seto A, Fukuyama H, Niijima K, Takenaka I, Kodoya T. Anaesthetic management of a patient with deep venous thrombosis using temporary inferior venacava filter. Masui 2000 Mar; 49(3): 302-4. J.

10. Ogawa N, Hayashi Y, Maehara T Sato S, Tobe M, Ozaki T, Hameda T, Uchida K. A surgically treated case of acute pulmonary embolism owing to deep vein thrombosis of the leg mainly caused by uterine myoma. Kyobu Geka 1992 Jul; 45(7):631-4. J.

11. Jensen KR. Deep thrombophlebitis in polycythemia and uterine fibromyoma. Ugaskr Laeger 1990; 152:2316. 
12. Kroger K, Rudofsky G. Duplex sonography of venous stasis. Angiology 1997; 48:523-8.

13. Osoba L, Ogden JR. Deep vein thrombosis secondary to compression by uterine leiomyoma. J Obstet Gynaecol 1998; 18: 397.

14. Wallach EE, Vlahos NF. Uterine myomas: an overview of development, clinical feature and management. Obstet Gynaecol 2004; 104: 393-406.

15. Lensing AWA, Prandoni P, Prins MH, Buller HR. Deep vein thrombosis. Lancet 1999; 353:479-485.
16. Weinmann EE, Saltzman EW. Deep-vein thrombosis. N Eng J Med 1994; 331:1630-1641.

17. Tsakok FH, Koh S, Chua SE, Ratnam SS, Tyler $\mathrm{CW}$, Layde $\mathrm{P}$, et al. Effects of norethisterone on coagulation and fibrinolysis in Asian women. Singapore Med J 1984; 25:442-8.

18. Rosendaal FR. Venous thrombosis: A multicausal disease. Lancet 1993; 353:11671173. 